\title{
PRODUÇÃO DE SANDÁLIA A PARTIR DE CÂMARAS DE AR E PNEUS - UMA ADAPTAÇÃO AO COTIDIANO BELENENSE
}

Isabela Sales Wanderley

isabela29sales@gmail.com

Nubia Suely Silva Santos

nubiatrib@yahoo.com.br

Resumo: O trabalho apresenta a pesquisa desenvolvida para a proposição de modelos de sandálias feitas a partir das câmaras de borracha de pneus, visando uma alternativa para o descarte incorreto deste material que se mostre eficiente no sentido de atribuir nova função ao mesmo, prolongando seu ciclo de vida e multiplicando o seu tempo de uso. Partindo de um problema recorrente das chuvas diárias que fazem parte do cotidiano dos moradores da cidade de Belém do Pará. O projeto apresenta técnicas manuais e simplificadas para a produção destas sandálias, havendo ainda necessidade de mais estudos que garantam a qualidade desejada às mesmas e a plenitude da aplicação do conceito de desenvolvimento sustentável: com a utilização exclusiva de materiais reaproveitados e de baixo impacto ao meio ambiente.

Palavras-chave: adaptação, Belém, pneumáticos, reaproveitamento, sustentabilidade

\begin{abstract}
This paper presents the research conducted for propose sandals prototype made of tires of rubber chambers, seeking an alternative to the incorrect disposal of this material that proves itself efficient to allocate new function to it, prolonging their life cycle by multiplying its time of use. Starting from a recurring problem of daily rains that are part of the daily lives of residents of the city of Belém, the project features manual and simplified techniques for the production of these shoes, there is still need for further studies to ensure the desired quality to them and completeness of application of the sustainable development concept: with the exclusive use of recycled materials and low environmental impact.
\end{abstract}

Keywords: adaptation, Belém, pneumatic, reuse, sustainability. 


\section{INTRODUÇÃO}

Este projeto visa o desenvolvimento de sandálias a partir da reutilização de câmaras de ar e de pneus, apontando para uma redução do consumo de novas matérias primas e a menor geração de lixo.

Além do uso de um material de difícil degradação a alternativa se mostra interessante também pelas características que o mesmo pode atribuir aos calçados. Sandálias e sapatos de borracha normalmente não tem pelo menos um dos itens a seguir: conforto, durabilidade, bom acabamento e baixo preço. A proposta em questão surge como uma alternativa para quem anda pelas ruas da Belém, em especial, pedestres, ciclistas motociclistas e quem faz uso do transporte público e que ainda deve se manter com boa apresentação para o desenvolvimento de suas atividades diárias: trabalho, estudo, lazer. Buscando solucionar este problema da maneira mais pratica; a borracha de câmaras de ar dos pneus foi apontada como alternativa viável e consideravelmente vantajosa em diversos pontos.

Por consistir em uma matéria de reaproveitamento, a medida contribui para o meio ambiente, pois estende o ciclo de vida da borracha, atribuindo nova função a ela assim que a mesma passa a não servir mais ao que foi prioritariamente destinada, fazendo com que seu tempo de vida útil seja consideravelmente maior.

O pensamento sustentável deve se dá a todo momento, o caminho para uma vida mais sustentável encontra-se justamente nas menores ações, mudanças nos processos de produção e no uso de recursos são pontos fundamentais nesta questão, no entanto nem um resultado será obtido sem que se tenha uma alteração efetiva no modo de consumo da sociedade atual. Kazazian (2005) aponta para um crescimento desenfreado do consumo, onde "em menos de um século, o número de objetos que nos cerca mais que decuplicou" (KAZAZIAN, 2005, p.45) ele fala ainda sobre a retirada de matérias-primas da natureza - as renováveis e as não renováveis - alertando para a difícil reposição desses recursos; consumimos em uma velocidade imensamente superior ao tempo necessário para que a natureza se recomponha e possa nos ofertar novamente estes recursos, por isso há necessidade imediata de repensar o consumo. O design deve ser um componente fundamental neste processo, pois, como afirma Victor Papanek:

O design preocupa-se com o desenvolvimento de produtos, utensílios, máquinas, artefatos e outros dispositivo, e esta actividade exerce uma influência profunda e directa sobre a ecologia. A resposta do design deve ser positiva e unificadora; deve ser a ponte entre as necessidades humana, a cultura e a ecologia. (PAPANEK, 1995, p. 31)

A câmara de pneu é um elastômero, composto por borracha natural e sintética além de outros materiais, sua cor geralmente preta é atribuída pelo uso de negro-de-fumo que (EMPRESA CHEMISOL, 201?) serve para deixar a borracha mais resistente protegendo-a também termicamente.

Sobre a história do surgimento das câmaras de ar é possível citar: "Mais uma etapa da história dos primórdios do pneu ocorreu no ano de 1845, quando Robert Thompson inseriu um invólucro repleto de ar no interior dos pneus de borracha sólida" (MÖDERLER, 2012, p. 615). Porém, ainda segundo Möderler (2012), fora somente após quarenta anos que John Boyd Dunlop, um veterinário escocês, revolucionou o transporte criando de forma improvisada uma câmara de ar de borracha flexível. 


\section{DESENVOLVIMENTO DE UM PRODUTO UTILIZANDO MATERIAL DESCARTADO DE PNEUS}

Serão apresentados neste capitulo as limitações do projeto e o desenvolvimento da pesquisa de acordo com a metodologia escolhida, tendo ao final as especificações da execução do protótipo.

\subsection{Limitações do projeto}

Apesar da elaboração de um resultado passível de uso, não serão apresentados neste trabalho testes que comprovem a resistência e a durabilidade do produto gerado, apenas a sugestão de técnicas e aplicação de materiais, que acredita se, com base nos estudos realizados, que possam tornar possível o alcance de tal objetivo, técnicas estas a serem estudadas e aprimoradas. Também não será realizado o protótipo com a aplicação do solado de pneu, tendo em vista o não domínio até então das técnicas necessárias para o corte e manuseio do mesmo.

\subsection{Metodologia}

Para o desenvolvimento da pesquisa fora aplicada uma versão adaptada da metodologia de Bruno Munari, onde, selecionou-se os itens de maior relação com o trabalho e acrescentou-se ferramentas que auxiliassem na coleta de dado e na geração de ideia; acrescentou-se ainda a etapa de "Resultados da Análise" que expõe de maneira mais direta os objetivos a serem alcançados. Com base nisso, definiu-se, portanto, a seguinte "série de operações necessárias". (MUNARI, 1981, p.10)

Problema - Definição do Problema - Componentes do Problema - Coleta e Análise dos dados - Resultados da Análise - Criatividade - Materiais - Modelo.

Para este trabalho fora tomada como última fase a etapa de "modelo" pois, como previsto nas limitações do projeto ainda não fora possível a realização de testes indicados para a etapa de verificação - tendo como consequência a também não realização da última etapa - Solução.

\subsubsection{Problema}

Como ponto de partida para o projeto obtive-se o seguinte problema: Utilizar material de pneus descartados para desenvolver um calçado adequado ao cotidiano belenense.

\subsubsection{Definição do problema}

A deposição de materiais e produtos após o uso é hoje um problema mundial, muitos países ainda não tratam o seu lixo, depositando seus resíduos sólidos no meio ambiente sem nenhum planejamento, ocasionando grandes danos para as comunidades e populações do entorno. Um exemplo disso são os pneus de automóveis, compósito feitos de polímeros elastoméricos, fibra têxtil e cabos de metal, que por tal complexidade tem grande dificuldade em ser reciclado, além de não ser um produto biodegradável; seu despejo sem controle no meio ambiente pode gerar grandes danos, como: poluição visual, contribuição para a proliferação de mosquitos transmissores de doenças e aumento dos riscos de enchentes nas grandes cidades. A reutilização desse tipo de material passa a ser, então, uma alternativa razoável para a redução do seu acúmulo incorreto. Por possuir a característica de impermeabilidade o material dos pneus é adequado para uso em situações de 
presença de água/umidade, mantendo sua integridade e durabilidade mesmo nessas condições, isso torna interessante seu aproveitamento em produtos/acessórios de vestuário para ambientes de clima úmido.

Por ser uma cidade intensamente chuvosa, e inclusive, famosa por sua tradicional chuva da tarde, Belém cria a necessidade de que seus moradores se adaptem das mais diversas formas; é comum, por exemplo, encontrar nas bolsas a pertences dos belenenses sombrinhas portareis e sacolas plásticas usadas para proteger da água seus objetos pessoais. Em meio a isso há ainda inúmeros problemas a serem solucionados; andar com sapatos de camurça, tecido e até mesmo couro não são opção viáveis neste contexto. Somando-se a isso, fora observado uma carência de alternativas para essa questão, empresas do ramo dos calçados parecem não ter se dado conta do potencial de mercado envolvido; não são ofertadas no mercado local sandálias completamente de material impermeável com qualidade mínima de acabamento, durabilidade, e, que estejam em uma faixa de preço acessível a este público. Há portanto a necessidade de suprir uma gama considerável de pessoas que sofrem com este problema; no geral é um público jovem, de classe média e média baixa, que estuda e/ou trabalha e utiliza principalmente o transporte coletivo para se locomover.

\subsubsection{Componentes do Problema}

Geração de resíduos, acúmulo de pneus, despejo incorreto, chuva e lama na cidade; calçados não resistentes; pouca variedade de produtos do mercado.

\subsubsection{Coleta e Análise dos dados}

$\mathrm{Na}$ coleta de dados buscou-se identificar que tipo de calçados disponíveis no mercado local poderiam se mostrar eficientes na solução do problema. Para ter uma visão mais consistente foi realizada uma pesquisa de similares com base em modelos que tivessem relação com o material, mecanismos e/ou aparência desejados para as novas sandálias. Essa coleta tomou como partido os Componentes do Problema; que apontam para a necessidade de um produto barato, confortável, durável e que resista à exposição frequente a água.

Fora feita uma pesquisa em lojas físicas presentes na cidade de Belém e em sites de vendas pela internet que comercializem sandálias. Observou-se que: das lojas físicas encontradas na cidade apenas uma é especializada em calçados plásticos ou de borracha (impermeáveis), está loja possui produtos de estilos variados e também os comercializa pela internet, no entanto, a maioria de seus calçados estão a uma faixa de preço considerada superior a que o público alvo está disposto a pagar. Existe ainda uma empresa que também atende ao critério de ser resistente à agua, visto que a mesma desenvolve calçados com pneus descartados e borracha natural (materiais impermeáveis) - atendendo, ainda, ao critério de consumo consciente - a mesma não possui loja física, mas está presente em outros estabelecimentos do ramo dos calçados e lojas de departamento; vende também pelo seu site e, diferentemente da anterior, está a uma faixa de preço de acordo com o público alvo. Outros modelos de sandálias impermeáveis são encontrados em outras lojas, porém, em número reduzido e geralmente com qualidade inferior as das outras duas empresas. 


\subsubsection{Pesquisa de similares}

Abaixo a apresentação dos similares que atendem ao critério de impermeabilidade - Figura 1- e de produção artesanal- Figura 2.

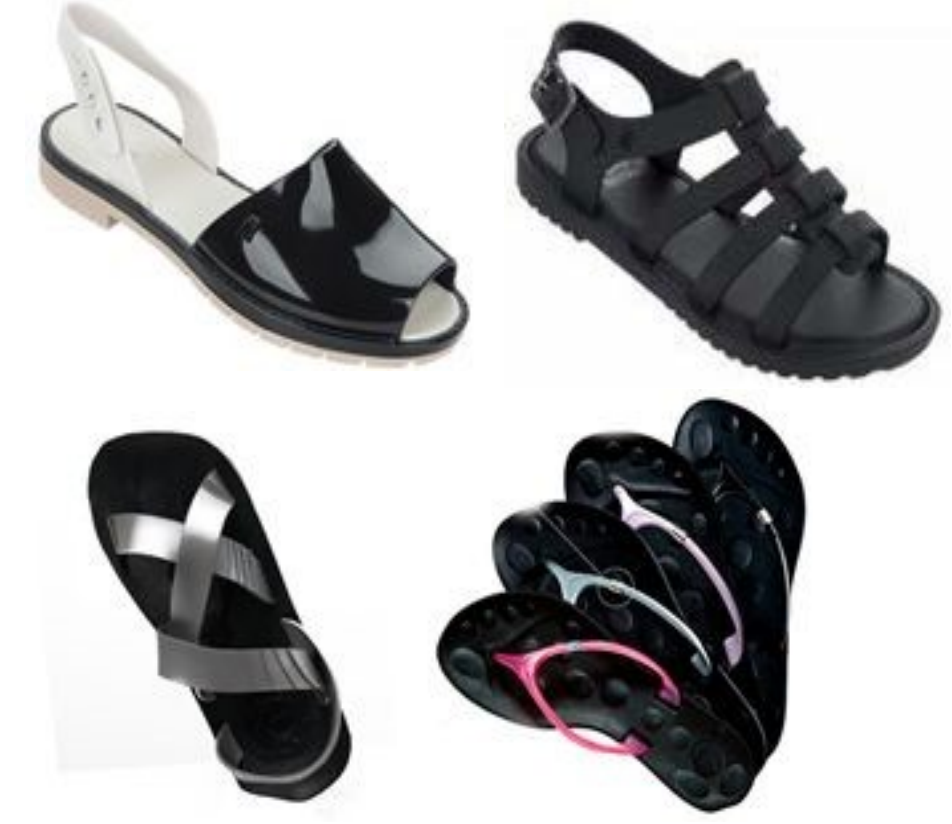

Figura 1- "Sandálias impermeáveis de produção industrial".

Fonte: www.lojamelissa.com.br(201?) e fonte:www.sapatos-femininos.com (2010)
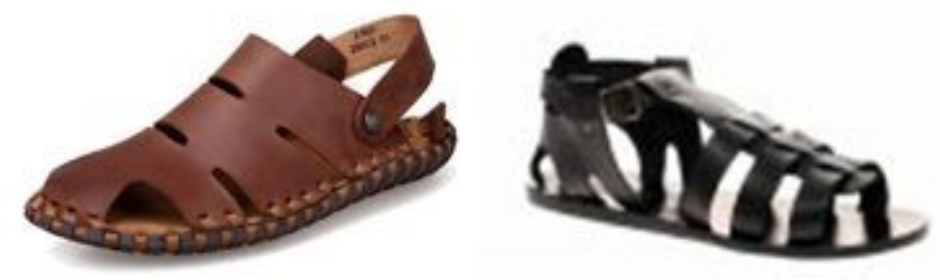

Figura 2- "sandálias de couro de produção artesanal".

Fonte: www.braziltrucks.com.br (2013)

\subsubsection{Resultados da Análise}

Com base nas questões apontadas pela pesquisa obteve-se a seguinte lista e especificações de critérios exigidos para a produção das sandálias:

- Resistente/durável: gerar uma sandália que resista às intemperes, podendo ser molhada sem que sua estrutura seja danificada ou que gere prejuízos a sua aparência, e ainda, que seque rapidamente para que continue sendo utilizada quase instantaneamente. $O$ produto também deve resistir bem ao uso continuo e ao longo de anos, para que não seja descartada com pouco tempo de utilização.

- Confortável: apresente ergonomia e sem objetos que machuquem.

- Com bom acabamento: para que a sandália tenha atratividade estética e que consiga atingir o item anterior.

- De baixo custo: para que possa ser uma alternativa viável ao público alvo. 
- De fácil execução: para possibilitar a produção artesanal, contendo preferencialmente poucas peças, materiais, ferramentas e técnicas acessíveis (de conhecimento popular). Poucos materiais- sendo todas ou quase todos impermeáveis

- Sustentável: que faça uso consciente dos materiais e recursos, evitando desperdícios e contribuindo com o ambiente, reduzindo a presença de resíduos sólidos do meio urbano.

\subsubsection{Criatividade}

Tendo em mente os componentes do problema elaborou-se um painel de estilo de vida - figura 3 - para melhor ilustrar as necessidades apresentadas no item 2.2.2 - definição do problema. Em seguida apresenta-se os esboços gerados - figura 4.

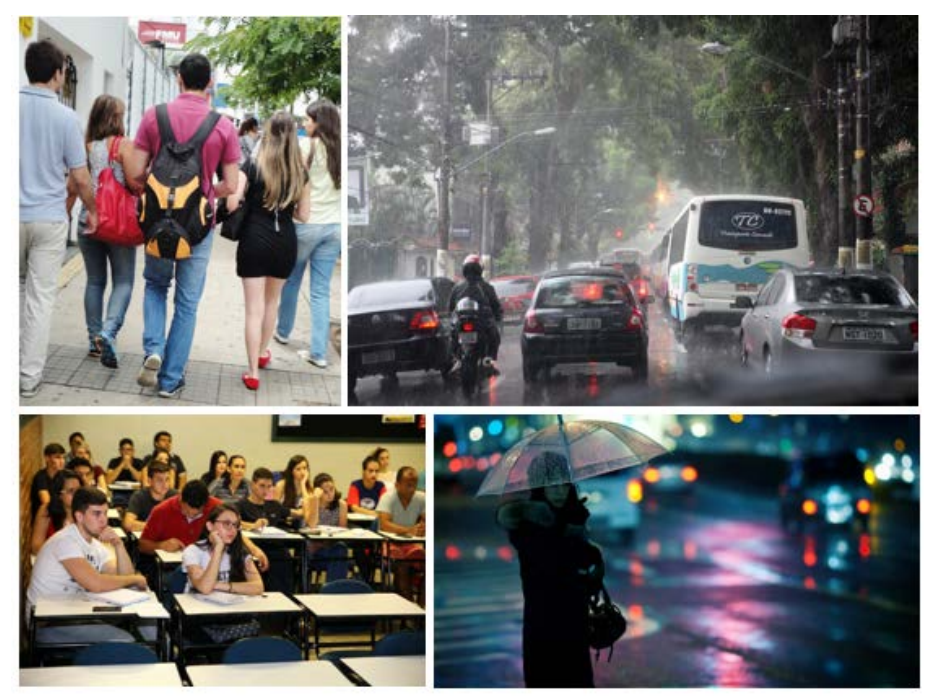

Figura 3 - "Painel de ilustração do cotidiano do jovem que trabalha estuda na cidade de Belém". Fonte: Acervo do autor.

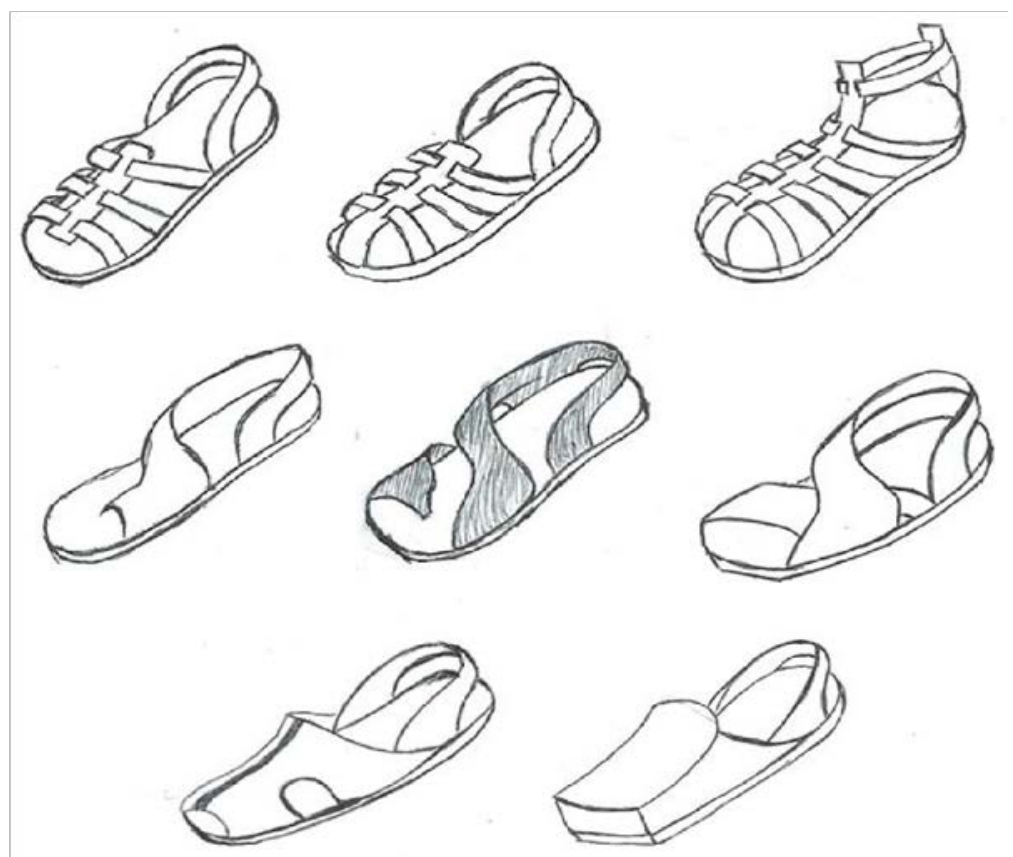

Figura 4 - "esboços".

Fonte: Acervo do autor 


\subsubsection{Materiais}

Para a escolha dos materais tomou-se como diretriz principalmente os seguintes requisitos: necessidade de produção artesanal, visto que não é desejado para o projeto uma produção com o nível de complexidade que se teria em uma produção industrial e nem o gasto de energia comumente exigido nesse tipo de atividade; baixo custo de fabricação; materiais de fácil acesso e impermeáveis.

Seguindo o pensamento de PAPANEK(1995) para o papel que o designer deve exercer na sociedade, retira-se novamente o trecho onde o mesmo afirma que: o design deve ser a ponte entre "necessidades humana, a cultura e a ecologia. (p. 31)

Com base nisso tem-se, portanto as câmaras de ar e os pneus como uma matéria prima que possa representar uma alternativa para o problema, onde os mesmos cumpre a função de ser impermeável, de baixo custo, fácil acesso e ainda ecologicamente correto.

Nas figuras 4 e 5 apresenta-se os materiais em questão - desejados para a execução do protótipo. Estando respectivamente: uma câmara de ar de pneu e um pneu. Também será utilizado cola instantânea de cianoacrilato - indicada para colar borracha - e lixa grossa para ajudar na colagem - dando maior aderência aos materiais.

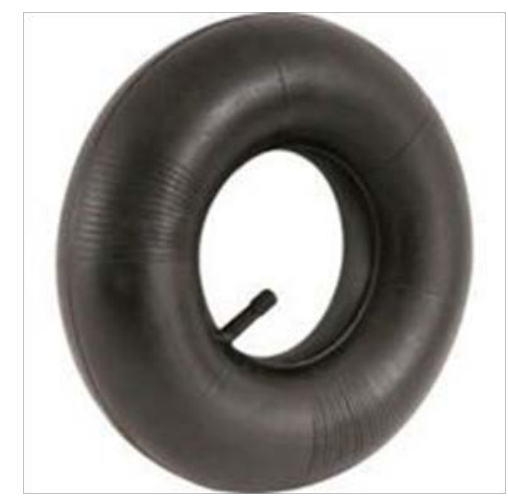

Figura 4- "câmara de ar de pneu". Fonte: www.vonder.com.br

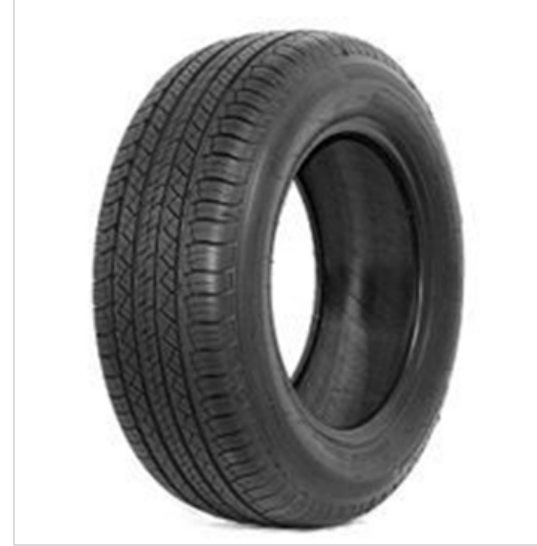

Figura 5- "pneu de carro".

Fonte: www.vonder.com.br

\subsubsection{Modelo}

Para o desenvolvimento do protótipo selecionou-se o projeto escolhido como mais simples e de mais fácil execução, as figuras 7, 8, 9, 10 e 11 mostram as etapas de fabricação do modelo. Nas figuras 12 e 13 são apresentados os o modelo pronto.

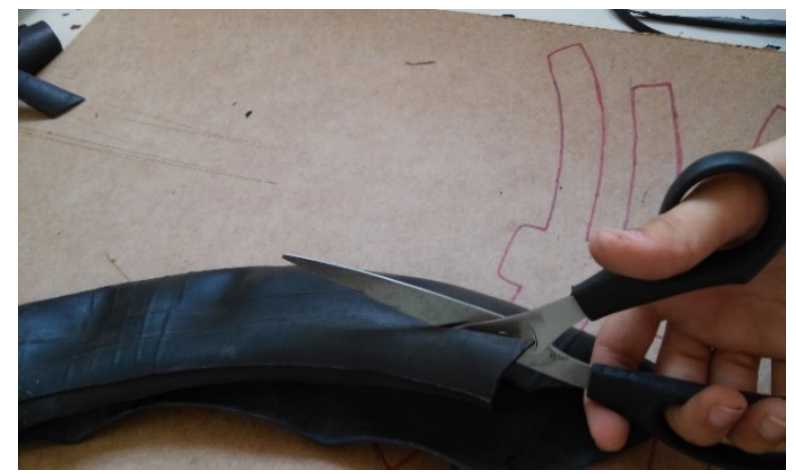

Figura 7- "Cortes básicos feitos com tesoura: abertura da câmara, corte da palmilha, corte dos filetes". Fonte: Acervo do autor. 


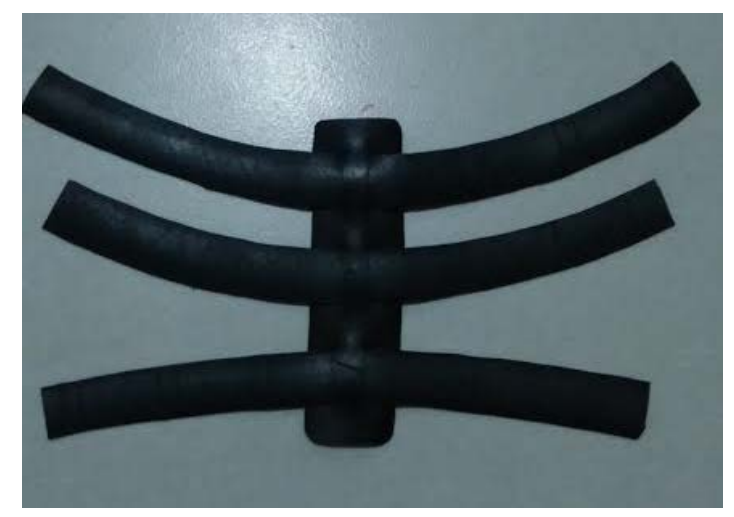

Figura 8- "tiras cortadas e encaixadas formando o corpo do calçado". Fonte: Acervo do autor

Foram usados grampos provisório que permitissem a marcação (com caneta) dos devidos lugares a serem colados as pontas das tiras, de modo a garantir ergonomia ao calçado. Como mostra a figura 9.

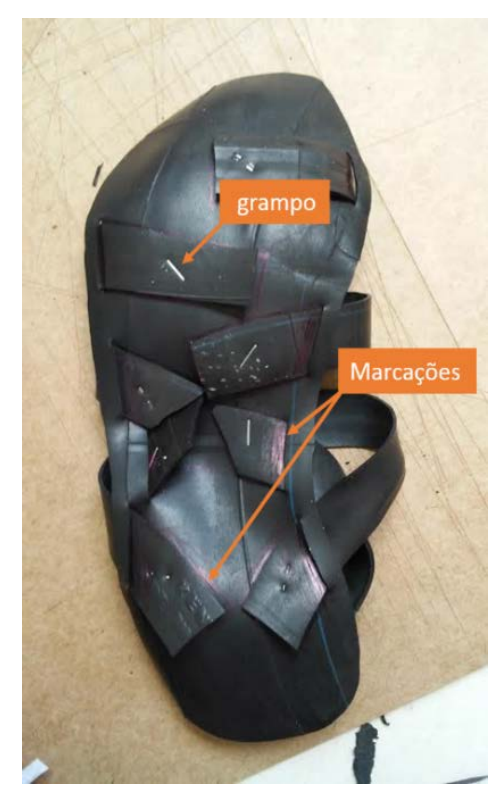

Figura 9 - "grampos usados para auxiliar a marcação". Fonte: Acervo do autor.

Após a colagem das tiras, outros pedaços de câmaras foram cortados e colados nos espaços vazios, preencheu-se o restante da palmilha atribuindo mais conforto à sandália. Figura 10. 
Figura 10- "preenchimento da palmilha" Fonte: Acervo do autor

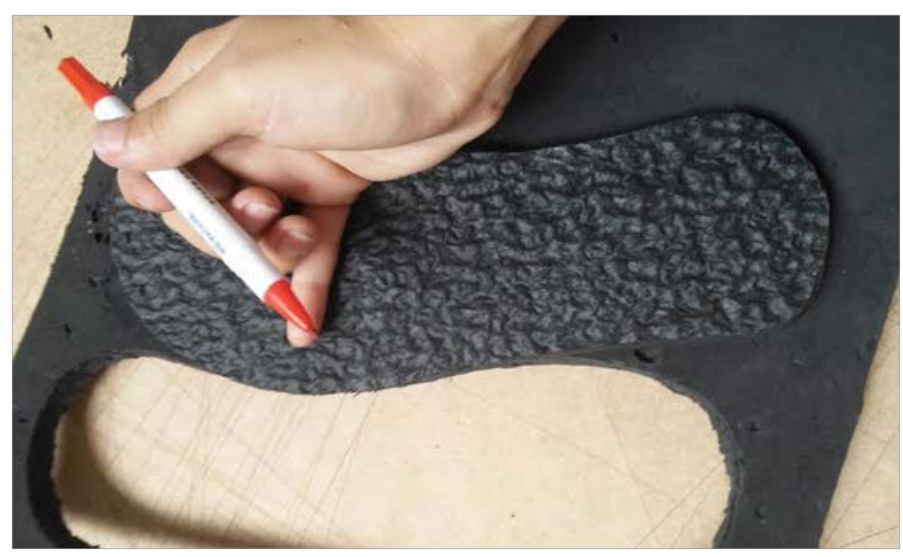

Figura 11- "Marcação com caneta para o corte feito com estilete do solado de látex".

Fonte: Acervo do autor

Após o corte do solado e da finalização da parte superior do calçado, aplicouse a cola na superfície lisa do solado, estando as duas partes - inferior da palmilha e superior do solado - devidamente lixadas, para conseguir garantir o bom desempenho da cola.

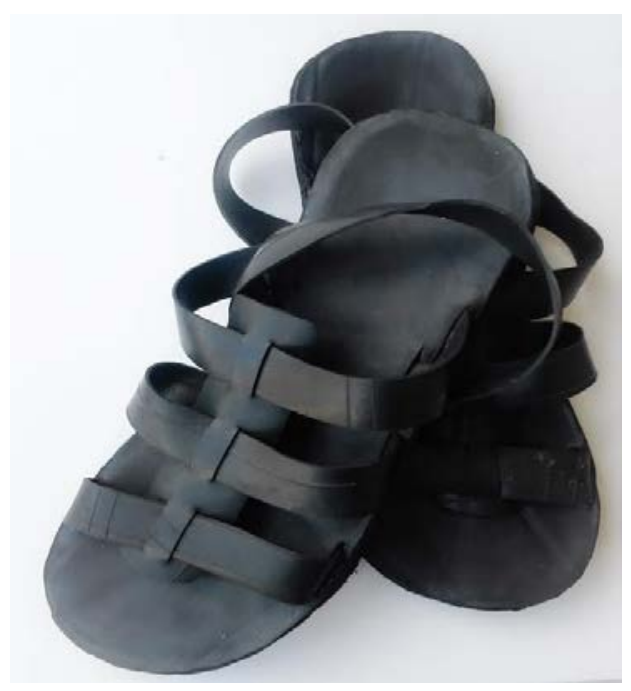

Figura 12 - "Sandália finalizada".

Fonte: Acervo do autor. 


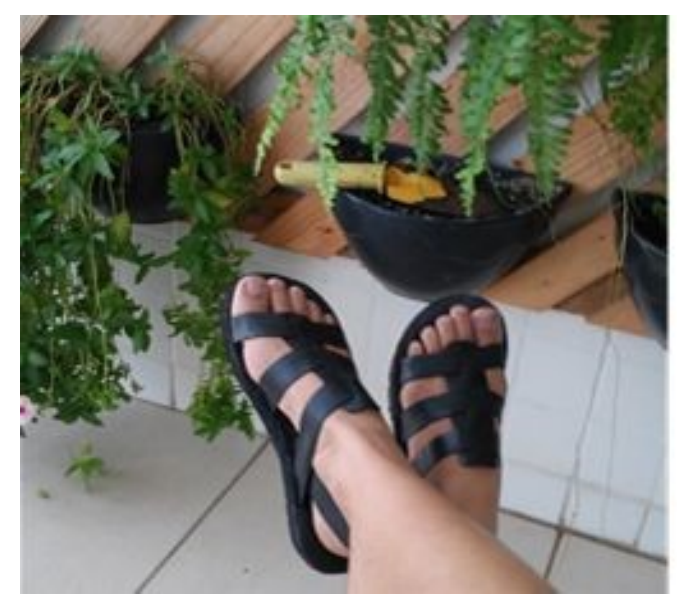

Figura 13- "Demonstração do calçado nos pés do usuário".

Fonte: Acervo do autor

\section{CONCLUSÃO}

Pode-se concluir que a pesquisa mostra-se relevante no sentido de apresentar o regionalismo e a análise do cotidiano local como importantes métodos de contribuição para o surgimento de ideias. A relação que se tem com o ambiente e o estilo de vida levado por determinados grupos sociais, são questões que não devem ser negligenciadas. O problema dos resíduos sólidos, especialmente os pneus, não se limita a uma região. Consiste em um problema crescente e universal.

A motivação pessoal de apresentar uma solução que garanta benefícios ao próximo, torna o projeto imensamente gratificante, criando o desejo de abranger grupos ainda maiores, é neste contexto que surgi a preocupação ambiental, questão fundamental para que se torne possível a existência das próximas gerações. O projeto possui dimensões pequenas, mas atenta para um ponto essencial do pensamento sustentável - a reutilização de materiais e produtos descartados, buscando evitar maior geração de lixo e o consumo desenfreado de recursos primários.

\section{REFERÊNCIAS}

MUNARI, Bruno. Das coisas nascem as coisas -2. ed. - São Paulo: Martins Fontes, 1981.

KAZAZIAN, Thierry. haverá a idade das coisa leves -2ª ed. São Paulo: SENNAC, 2005. PAPANEK, Victor. Arquitectura e design. Ecologia e ética. 1a ed. Lisboa: Edições 70, 1995.

WERLANG, Rafhael; SILVEIRA, Fernando. A física dos pneumáticos. RS

<http://www.if.ufrgs.br/ lang/Textos/Pneus.pdf> Acesso: 23/05/2016.

EMPRESA CHEMISOL. Negro de Fumo - características e aplicações. 2016

em:<http://www.chemisol.com.br/produtos/negro-de-fumo/>Acesso:09/06/2016. 